Session 2547

\title{
Applying a Global Ethic in Engineering Organizations
}

\author{
James E. Globig \\ University of Dayton
}

\begin{abstract}
$\underline{\text { Abstract }}$
The 1980s and early 90s were times of design and manufacturing "catch up" for many companies. The American consumer began to look to other countries to satisfy their demands as the label of "Made in America" came to be seen as shorthand for increased cost and low quality. In embarking on the new product catch up era, many manufacturers chose to terminate their technical and middle management employees and adopt "outsourcing" as a way to acquire labor, new products, and sub assemblies without incurring the financial and legal risks of designing and manufacturing their own products. This era has left a mark on American industry in general and the engineering profession in particular that remains today. Ethical considerations, although not completely disregarded, have been largely cast aside so that at any critical juncture in decision making, the paramount question to be answered by the engineer becomes "Is it legal?" as opposed to "Is it ethical?" This paper attempts to define a global ethic and applies it to ethical issues commonly experienced in engineering organizations. Finally, this paper outlines how our engineering curriculum can be designed to address ethical issues and includes a case study to illustrate them.
\end{abstract}

\section{Applying a Global Ethic in Engineering Organizations}

\section{INTRODUCTION}

Much has been written about ethics in engineering. The vast majority of the early and present day contributions in the area emanate from civil engineering, chemical engineering and bioengineering. Not surprisingly, these fields can and do have significant impact on the quality of human life and much of the research exists because of the widely accepted values based on the sacredness of human life. Explicit illustrations of moral dilemmas and widely accepted solutions readily come to mind: We do not design overpasses that collapse in earthquakes, we do not design space shuttles that explode when it gets cold ${ }^{1}$ and we do not experiment with human life when the results are not well understood. These "typical" cases of engineering ethics are indeed excellent illustrators of basic moral principles. Unfortunately, the vast majority of the contribution to engineering ethics addresses the engineer only as a designer.

Because of the corporate downsizing of the 80s and 90s and subsequent functional consolidation, engineers have become increasingly integrated into the day-to-day organizational decisions in such areas as product management, marketing, purchasing, and human resources. Many engineers find themselves far removed from directly and substantively

Proceedings of the 2001 American Society of Engineering Education Annual Conference and Exposition

Copyright $\odot 2001$, American Society of Engineering Education 
impacting the quality of human life. As such, the direct discussion of ethics in the everyday industrial setting is increasingly rare. Ethical considerations are now subsumed into concerns of what constitutes a "good business decision", "what is best for our shareholders" or even "how can we avoid a lawsuit." Instead of confronting the ethical dilemmas directly, today's engineer, with an expanded role in the corporate organization, now looks implicitly to other disciplines (management, finance, law) for guidance and, at times, to convince oneself that there are "acceptable" reasons for being less than ethical when planning projects, managing human resources, and specifying and purchasing products. The degradation of ethics in engineering organizations is only a symptom of what many philosophers have observed as a global trend that permeates our societies, our politics and even our families. ${ }^{2,3}$

\section{ABSOLUTE VALUES}

In researching the subject matter of ethics in engineering, the terms ethic, moral, and law are used frequently and interchangeably. If they are to be used properly and we are to understand their meaning when conducting research or otherwise addressing the subject, however, then we need to understand their meanings and how they differ:

From Webster's Dictionary:

\section{Ethic}

1. "The discipline dealing with what is good or bad and with moral duty and obligation.

2. A set of moral principles or values."

\section{Moral}

1. "Of or relating to principles of right and wrong in behavior.

MORAL implies conformity to established sanctioned codes or accepted notions of right and wrong.

ETHICAL may suggest the involvement of more difficult or subtle questions of rightness, fairness or equity."

\section{Law}

1. "A binding custom or practice of a community: a rule of conduct or action prescribed or formally recognized as binding or enforced by a controlling authority."

Undoubtedly, these terms are related. As can be seen from the above definitions, however, "ethic" and "moral" share a subtlety by focusing on principles of good and bad or right and wrong that is less apparent in the definition of law. Unfortunately, in today's industrial age, law or "what is legal" has taken on a greater concern so much so that one can argue that it often supplants the role of ethics in corporate decision making. The problem with law overtaking ethical considerations is apparent in the very definition: what is "formally recognized" "binding" or even "enforced" may vary greatly by place and time so that the question of "is it legal" quickly dissolves into "will we get caught?" Clare Booth Luce has an excellent example of the difference between the law and morality: "There is no law that requires a person to speak the truth, unless he is under oath to do so in a court proceeding. A person can, with legal 
impunity, be a habitual liar. The traditional morality of our society, however, takes a dim view of the habitual lair. Accordingly, society punishes him in the only way it can--by social ostracism." ${ }^{2}$ Stated simply, our moral and ethical responsibilities must go beyond the limitations of the law. ${ }^{4}$

So what are our basic ethical principles for engineering? One might direct fellow engineers toward the engineer's codes. These codes have been the ethical baseline of our profession and still serve that purpose under many circumstances. The codes, however, were written by engineers in the context of their own industrialized culture but in today's global economy, some of the morals and ethics shared by western cultures are not shared by others. In fact, assuming that other cultures, and in many cases individuals within our own culture, accept the engineers' codes or some other code is not only naïve but can lead to difficulties ranging from simple misunderstandings to absolute failure of a technical or commercial relationship. Some codes are a lengthy, detailed, almost dogmatic, set of rules directed solely at a specific field that do not lend themselves to everyday use. On the other hand, other ethical codes confuse ethics with other desired behaviors. For example, The Fundamental Principles of The "Code of Ethics of Engineers" on the ABET Web Site ${ }^{5}$ are as follows:

- using their knowledge and skill for the enhancement of human welfare

- being honest and impartial, and serving with fidelity the public, their employers and clients

- striving to increase the competence and prestige of the engineering profession; and

- supporting the professional technical societies of their disciplines

Although the first two bullets describe ethical behaviors, the latter two, although admirable qualities, do not.

In analyzing the need for engineers to follow an engineer's code, Michael Davis ${ }^{6}$ states, "Engineers do too many things for the standards [codes] to apply to all" and the variety of codes "could make it hard for an engineer to know what to do." On the other hand, Davis sites an example of when the engineer's code of ethics should have been used in the decision making leading up to the Space Shuttle Challenger disaster. Referencing Robert Lund's (vice-president for engineering at Martin-Thiokol) fateful decision to launch the Challenger on an unusually cold day, Michael Davis states that Lund "was not free to take off his engineering hat (though he could wear other hats in addition)." Further supporting why engineers should use their code of ethics, even when in a management capacity, Davis states "Managers are not professionals in the strict sense. Though managing now has schools like those of other professions, managers lack two features essential to professionals strictly so called, 'first a formal commitment to a moral ideal and second, a common code of ethics!'" Notwithstanding the suggestion, there is, nevertheless, a substantial amount of research being conducted on identifying a common code of ethics, one basic moral code, that is intended to not only guide all professions but all human activity. 


\section{Baseline Global Ethic}

Rushworth M. Kidder ${ }^{3}$, in his article entitled "Universal Shared Values" stated "There is a pressing need for shared values in our age of global interdependence without consensus." Is there a set of moral and ethical principles shared by mankind or at least most cultures that are likely to conduct business with each other? Many philosophers say yes with the caveat that some cultures stress some morals more than others. ${ }^{2,3}$ Has the set of principles been sufficiently refined and put into print? From the research conducted for this paper, one could easily conclude, "No", at least not to the point where any broad based consensus is shared within the philosophical community. In fact, there is another camp where philosophers are "construing ethical problems as irresolvable conflicts between opposing principles or obligations". ${ }^{7}$ If one combines, however, the efforts of some philosophers and others searching for a global ethic ${ }^{8}$ there is a startling commonality among their conclusions. Hans Kung ${ }^{8}$ has conducted the most exhaustive research including Buddhism, Christianity, Native religions, Hinduism, Judaism, Islam, Sikhs, and Inter-religious organizations from nearly all parts of the globe. Each of the "Baseline Global Ethics " outlined below are identified in the works of Hans Kung ${ }^{8}$, Rushworth Kidder ${ }^{3}$, Clare Booth Luce ${ }^{2}$, and Keshavan Nair ${ }^{9}$. All talk about the following ethics as the baseline among multiple cultures and religions. These universal principles compiled from their works may not be all inclusive but they are undoubtedly the baseline.

\section{Do unto others as you would have them do unto you.}

The Golden Rule can be found as a prominent ethic in almost every culture. This macro ethic is identified as the basis for almost all other morals in almost every reference. It is sometimes described as fairness and justice. At its roots is the concept of equality among different individuals, sexes, cultures, religions, and races.

\section{Respect for Life}

Inflict no pain or harm on another person. Compassion, non-violence and love for others. Responsibility for others well being.

\section{Truthfulness and Honesty}

This principle includes both oneself and others. Implicitly, this includes another virtue that is so universal it is often listed separately - responsibility for ones actions.

\section{Unity of Mankind}

Strive to move mankind toward solidarity and partnership and to pursue the common good. Respect and love one another. Loyalty to all mankind.

\section{Unselfishness and Service to Humanity}

Also described as hospitality.

\section{Tolerance and Respect}

A sense of moderation which includes those who think differently.

\section{Courage}

The "willingness to take risks and a readiness to sacrifice"7 to make a fundamental change. 


\section{THE APPLication OF THE GLOBAL ETHIC TO ENGINEERING ORGANiZATIONS}

\section{Management of A Product or Process Development Team}

Many companies have or are moving toward the Cross-Functional Team (CFT) as the core of their organizational design. The advantages of CFTs are many ${ }^{11}$, especially when applied to those functions requiring high-level integration of diverse areas of expertise--such as Product Development. Because of the crucial role engineers play in the product development process, leaders of product development teams are frequently engineers. Additionally, companies that employ CFTs usually have done so in an effort to "reduce" middle management overhead and employ the synergistic effects of teamwork, communication, and co-location of personnel. This puts the engineer as manager in the role of market manager, program manager, human resources manager and purchasing agent. In this scenario, ethical decision-making extends beyond the design process and the engineers' code. After all, poor design and misuse of the engineers' code did not cause the Challenger disaster, unethical program management did. ${ }^{12}$

\section{The Engineer as Market Manager}

One of the quickest ways to get a program approved and to increase one's value to the organization is to claim huge market success (high price and big forecast) of the new product. This one metric is a major driver of revenue and profit--in the numbers of units sold, in the minimization of the cost/unit, of market share, and of stock value. The impact of this one parameter on the program approval process is so substantial it frequently is abused more than any other factor. And why not? Forecasts are just that, so its is easy to confuse the ethical difference between a forecast that is within $+/-5 \%$ of actual sales and one that is $50 \%$ too optimistic. "So what if I inflated the forecast a little, it doesn't hurt anybody". Although this statement is probably true when it is truly a "little" inflated, forecasts that miss by a large percentage can, and often do, affect peoples' employment. On a basis relative to the size of a company, large product development programs consume large amounts of money and when that investment is not paid back with sufficient profit, companies must reduce their costs frequently by terminating people.

If we were to apply the Baseline Global Ethic to these marketing techniques and truly understand the direct and indirect impacts on our organization and its members, we would conclude that inflating unit and price forecasts is simply not truthful. In this case being untruthful also is not respectful or compassionate because this person would not be taking responsibility for others well being in his organization. It is not unselfish since the only reason to untruthful about a forecast is to get your program approved and to increase your (short term) status in the organization. A more ethical approach to this dilemma would be to conduct a more objective market survey and perform a best / expected / worst case analysis and include all three scenarios in the forecast. 


\section{The Engineer as Program Manager}

It is no longer an infrequent occurrence for development programs to grossly underestimate development times and costs? Some of the largest software producers in the world commonly miss release dates by several months and sometimes over a year. Are these mistakes? Sometimes, certainly. But often program cost estimates are either carelessly made (lack of respect) or deliberately misrepresented (dishonest) in an effort to get a program approved and increase our own, albeit short term, value (selfishness). If nothing else, program managers who lack the courage to tell the truth about the status and costs of their programs would eventually reduce their credibility and ultimately their value to the organization.

\section{The Engineer as Human Resources Manager}

When the engineer is asked to take on the role as human resource manager, she should recognize a responsibility to resolve interpersonal conflicts and address performance issues promptly when they arise. To avoid addressing a performance issue of an employee until the annual performance/compensation review is simply not courageous. One would not be responsible for the employees well being because a performance issue left unaddressed prolongs and increases the negative impact the employee has on the company and on others. It is not compassionate because one would not be giving the employee the earliest opportunity to correct the issue.

In times of budget cutting and reductions in force, there often is not enough money to compensate employees. A common practice under these circumstances is to dictate unachievable objectives or to utilize "other" criteria with which to assess performance and compensation. Often times this permits the manager to rationalize, to oneself as much as to the employee, a very low increase in compensation or the outright termination of the employee. An example of these "other" criteria are such statements as "she/he isn't a 'team player'" which frequently means he fails to do what we tell him to do or she questions our decisions. Another example of these "other" criteria are statements like "he doesn't have a degree" neglecting to recall that he has been performing engineering duties for 30 years. Assessing performance by creating "other" criteria which have no direct connection to performance is dishonest and indicates a lack of tolerance and respect for the employee. Whether an employee thinks differently about a design decision or took a untraditional path to gain engineering expertise may have no connection to performance. Organizations use these "other" criteria to artificially create a poor performance review believing they are avoiding conflict or legal action by an employee who would otherwise get a positive performance review but, due to current financial circumstances, no salary increase. There have been numerous studies done on the relationship of compensation to motivation. What appears to motivate employees is compensation in relative terms. In other words, if a budget for only a $2 \%$ increase in overall salary for a Product Development Team exists, then a high performing employee is usually just as motivated with a 
$3 \%$ increase as they are with a $6 \%$ increase -- provided they understand that the overall pool is only $2 \%$. Moreover, many other forms of compensation are nearly as effective as money-recognition, awards, special privileges, etc. On a short-term basis, these other forms of compensation are often even more effective than a small salary increase. The honest, courageous way to manage performance and compensation is to separate their scales. If an employee is a high performer, it is honest to tell them so in writing and to be courageous by explaining that the compensation budget is restricted and what the value of their compensation was relative to others. In addition, utilize other ways to recognize contributions. The vast majority of employees will appreciate this treatment and will stay with the employer in good times--and in bad.

\section{The Engineer in the Purchasing Process}

Engineers still play significant roles in purchasing either as the purchasing agent and / or as the specifier or user of the purchased materials. However, a change has occurred in that many corporations have centralized their purchasing function in lieu of the more traditional and autonomous function associated with each individual site or manufacturing operation. This consolidation allows larger organizations to utilize combined volumes to buy materials, outsource sub-assemblies, and even outsource entire products at lower prices. This change, coupled with the use of common materials and sub-assemblies throughout the corporation, has in fact substantially reduced operating costs.

The centralization of the purchasing function has, however, some negative, albeit indirect, side affects. This change has removed purchasing personnel from their internal end users and has separated the suppliers from the end user to the extent that the only communication between them is frequently only through documentation. Further, this documentation is typically filtered through a centralized purchasing function.

The negative side effect is that it allows suppliers to take greater advantage of "specsmanship." Specsmanship is the term for publishing product or process specifications in such a way as to promote your product over your competitors'. Specsmanship can be practiced in an ethical fashion. Unethical specsmanship, however, involves publishing specifications that are not worst case, often are not even typical, sometimes cannot be achieved under any operational circumstances. In addition, the way some of these specifications are published makes them appear as if they are worst case. An obvious area where specsmanship is often abused is in operating temperature range. For example, publishing operating temperature specifications at $25^{\circ} \mathrm{C}$ are worthless and misleading on an instrument that is to be used outdoors or even on the factory floor experiencing large fluctuations of temperature. Now comes an overworked buyer with aggressive cost reduction performance objectives comparing one suppliers misleading, room temperature specifications against another suppliers worst case specifications as if they were equivalent. Another example of specmanship is the inclusion of a particular function (that is a point of comparison with the competition) that is either difficult to access, incomplete, or impractical in some other way just so one can include that function in the list of other functions that appears in their catalog or advertising literature. There are numerous examples of overall utility and quality that are either glossed over or not addressed in manufacturers specification sheets: stability over time, durability, repairability, number of category one software bugs, 
"accessories" that are essential but not included in the base price, etc. In some organizations, specsmanship has not only moved into the realm of dishonesty but has also become an acceptable custom or practice. It requires courage to acknowledge that some portion of your product or process might not be as good as the competition's (assuming they have not practiced dishonest specmanship). At its worst, dishonest specsmanship shows a disrespect for life and can directly or indirectly cause permanent damage to or loss of another's life ${ }^{1}$.

Another negative but indirect side affect of the centralization of purchasing is the billing of customers by suppliers for services not requested and in some cases extra services that are required but through the fault of the supplier! Today, it is common practice for suppliers to bill customers for expensive overnight delivery because the supplier's manufacturing operation failed to produce the product in time for shipment at standard costs. Because the end user is now removed from the purchasing process, they are usually not consulted on the shipment method even though they are the ones charged for the shipment costs. Dishonest billing is a selfish practice when an at-fault supplier lacks the courage to absorb the extra costs of getting product to a customer on time.

Because of centralized purchasing, one of the last remaining "officials" to referee the purchasing function, the end user, is now off the field. This is not to blame dishonest specsmanship and billing practices on the centralized purchasing trend. The role of purchasing is to supply their internal customers with the best value that meets their requirements. However, the purchasing agent is usually not the end user and can only tell so much from a less than forthright manufacturers' specification sheet and shipping policies. In addition, the centralized purchasing agent usually does not have first hand information about the end users level of urgency to receive the purchased material. Therefore, it is left up to the engineer who frequently performs the purchasing function and who designs and documents our products and processes, not to remove ourselves from the ethics of the purchasing process by rationalizing that "the competition does it."

\section{The Young Engineer - A Product Of THE ‘90S}

Do these business practices physically hurt anybody? Hopefully not. Respect for life is not, of course, the only global ethic. According to the fundamental principles of the Code of Ethics of Engineers on the ABET web site ${ }^{5}$, "Using our knowledge and skills for the enhancement of human welfare and being honest and impartial, and serving with fidelity the public, their employers and clients" oversimplifies the every day decisions engineers must make. At work, at school, in the newspaper, in the Capital, and around the world ethical issues are running rampant. Engineers and educators are not addressing them effectively and our young people are beginning to accept them as normative behaviors. ${ }^{10}$ Clare Boothe Luce writes, "Campus surveys show that one-third of our college students say they would cheat if they were sure they would not be caught. Forty-five percent say that they do not think that it is necessary to lead a moral life in order to be happy or successful. Sociologists note the extraordinary increase in blue and white collar dishonesty, such as sharp business practices, dishonest advertising, juggled books and accounts, concealment of profits, and the taking and giving of bribes. These are all practices which rip-off the buying public." ${ }^{2}$ The Golden Rule has now become "Do unto 
others what you can get away with." Finally, these practices certainly do not reflect solidarity and respect for our global family.

\section{ETHICS IN THE ENGINEERING CURRICULUM}

As illustrated in this paper and in the case in the appendix, day to day ethical decision making, even in engineering, does not usually involve issues typically associated only with engineering. For this reason, it is important that our students understand the concept of a universal moral code and how such a code might apply not just to our professions and careers but also to everyday life. This understanding typically comes at the later stages in our moral development:

"Lawrence Kohlberg hypothesized six different stages or moral philosophies through which people can pass as they develop.

Stage 1: A morality focusing on obedience - yielding to the wishes of those who are more powerful and thus avoiding punishment.

Stage 2: An instrumental morality that seeks personal benefit with little concern for the needs of others....

Stage 3: Amorality that seeks to maximize the quality of relationships. A person does what will gain other's approval.

Stage 4: A morality of law and order: One has a duty to obey the law and maintain social order.

Stage 5: A morality that focuses on social contract: What is moral is what people have previously agreed to.

Stage 6: A morality that uses abstract, universal ethical principles to decide what is a moral act. reasoning at this stage respects all people without regard to their ethnicity, age, class, or other personal characteristics."10

Stages 1 and 2 are known as Preconventional. Most people, including college undergraduates, primarily use the moral reasoning of Conventional Stages 3 and 4 . Post conventional Stages 5 and 6 involve using principles to think about relationships among people rather than rigid laws. ${ }^{10}$

It is not logical to conduct our professional life on a moral basis different from our personal life. As Caroline Whitbeck observes, "we are doing our students a disservice by assigning casework or other scenarios with 'cookbook', 'doing the right thing' solutions. More often than not, ethical decision making is about pursuing multiple 'good' solutions simultaneously and then selecting the solution most just for all persons (or issues) involved." 7

Richard Conway ${ }^{13}$ also provided some applicable advice:

1. Provide relevant cases--if the cases don't seem plausible you won't engage the students.

2. Ask questions to facilitate reflection, especially on the nuances of the case. 
3. Allow students to disagree and struggle with the issues. If you have selected good cases there will undoubtedly be multiple "right" answers and some answers not everyone will embrace.

As does Lion Gardiner ${ }^{10}$ :

4. Have students play the roles of and explain the reasoning used by others to resolve moral dilemmas.

5. Ensure all students have ample out of class contact with faculty members.

6. Directly teach Kohlberg's model of six stages of reasoning as one would teach other disciplinary concepts.

\section{DISCUSSION:}

What would transpire if we started using the words that really describe our actions? What if we used personnel again in place of "human resources"? What if we used firing people instead of "lay-off" or "reduced" or "re-engineered"? It may serve to put humanness back into our every day decision making and cause us to pause and examine the ethics of actions and their impact on others.

Internal politics, selfish decision making, the careless collection or misrepresentation of facts, and the disregard for and disrespect of the individual under the guise of what is good for the organization are compromising the common good on a global scale. When engineers' actions compromise the ability of their employers' to make sound decisions, they also compromise their employer's ability to provide long term employment. In every example in this paper, an ethic as basic and simple as the golden rule was violated along with the other ethics mentioned.

Interestingly, not one of these ethical violations is illegal unless taken to extreme resulting in significant financial damage or personal physical harm.

Our educational institutions, our organizations, and their leaders must recognize that practicing and reinforcing basic ethics is a lifelong process; not something learned only in our formative or pre-conventional years. The ideal venue to reverse this trend is in the relevant and recurrent moral and ethical education of engineering students. The case study that follows illustrates some of the issues addressed in this paper. It is a compilation of interviews of individuals from a variety of organizations. For obvious reasons, the names of the organizations and individuals in the case are fictitious. This case may be used in Project Management, Engineering Management, Engineering Ethics, Business Ethics, Introduction to Engineering or any other course addressing common moral or ethical issues in engineering or business. 


\section{BIBLIOGRAPHY}

1. Bell, Trudy E. and Esch, Karl. "The fatal Flaw in Flight 51-L" IEEE Spectrum, 24 Feb, 1987, pp. 36 - 51

2. Luce, Clare Booth. "Is The New Morality Destroying America?" Human Life Review, New York, Winter 1999, pp. $15-26$

3. Kidder, Rushworth M. "Universal Human Values" The Futurist, Washington, July / August 1994, p. 8

4. Mucha, D. Michael. "Is it Necessary to Compromise Engineering Ethics to Remain Competitive in Today's Marketplace?" Civil Engineering, May 1994, pp. 62 - 63

5. http://www.abet.org/Code_of_Ethics_of_Engineers.htm

6. Davis, Michael. Thinking Like an Engineer, New York, Oxford University Press, 1998

7. Whitbeck, Coroline. "Ethics as Design: Doing Justice to Moral Problems" Hastings Center. The Hastings Center Report, Hastings on Hudson, May / June 1996, p. 9

8. Kung, Hans and Kuschel, Karl-Joseph. A Global Ethic, London, SCM Press Ltd, 1993

9. Nair, Keshavan. A Higher Standard of Leadership: Lessons from the Life of Gandhi / Keshavan Nair, San Francisco: Berrett - Koehler; Emeryville, CA: Publishers Group West [distributor], c.1994

10. Gardiner, Lion F. "Fostering Student's Moral Development" Teaching Excellence Vol. 11, No. 5, 1999 2000.

11. Globig, James E. “The Engineer 2000,” ASEE - Engineering Technology Division’s The Technology Interface, Fall 1999

12. Johnson, Deborah G. Ethical Issues in Engineering, Englewood Cliffs, New Jersey, Prentice Hall, 1991

13. Conway, Richard. "Teaching Ethical Decision Making” The Teaching Professor, May 1999, p. 6

\section{JAMES E. GLOBIG}

Prof. Globig joined the University of Dayton in August 1998. With nearly 20 years of engineering experience in a variety of different product producing organizations, he combines a practical and thorough understanding of the role of the engineer in corporate America. Jim demonstrates an in-depth understanding of the development process through the utilization of high performance cross-functional teams to execute on schedule and on budget releases of high quality new products. He is experienced in both analog and digital electronics. 


\title{
CASE STUDY
}

\section{Organizational Design and Engineering Ethics}

\author{
JAMES E. GLOBIG \\ Assistant Professor \\ Dept. of Engineering Technology \\ University of Dayton
}




\section{MEGAMATION}

\section{INTRODUCTION}

Megamation is a publicly held company based in Lake Tahoe, NV. Megamation designs and manufactures automation systems for the automotive industry. Megamation has two divisions with three semi-autonomous operations; the Robotics Division and the Automation Systems Division (ASD). The Robotics Division has two operations plants in Boise, ID, and Detroit, MI. The Detroit facility is the site of the original robotics plant and remains the home office for the Robotics Division. It is also the only facility that is unionized (See Fig. 1). There are two major components to the Robotics Divisions business; the internal market and the external market. The Detroit Operation and the Boise Operation make robots and they sell them internally to the Automation Systems Division in Phoenix, AZ and externally to automation systems integrators throughout the world. Because the Detroit plant was the original facility, their manufacturing equipment is dated and therefore Detroit Operations has been having difficulty supplying their sister plant and the external market with cost competitive components.

Recently, there have been some changes in the automation industry. Increased competition from the Pacific Rim has forced U.S. based automation manufacturers to make deep cuts in their costs including the areas of direct labor and overhead. The automotive industry was also experiencing the same global pressures and had already laid-off thousands of human resources in the mid-west resulting in high unemployment rates for both white and blue collar resources.

\section{Background of Butch Phist}

It was clear to Butch Phist, now President of the Robotics Division, that the Detroit manufacturing operations, with their high cost of labor and antiquated manufacturing equipment and processes, were not going to be able to compete in the global economy much longer. Butch was transferred to Detroit from Lake Tahoe. Butch's former position was corporate Chief Financial Officer (CFO) in Lake Tahoe. He was recently transferred to Detroit and was given two years to transform the Robotics Division into a global cost leader.

\section{Butch Phist - Chief Financial Officer}

It was just last year that Butch was promoted to CFO. (Fig. 2) When he became CFO, Butch designed and spearheaded a re-organization that centralized the purchasing function at the home office of each division. Butch thought that his purchasing re-organization plan was brilliant, as did Al Loof, the CEO of Megamation. First, Butch limited each General Manager (GM) to a budget of only a $1 \%$ increase (of overall salary) in compensation for their purchasing function. In addition, Butch analyzed the cost savings of each buyer as a result of their negotiating price reductions from their suppliers. Then, he selected the four buyers with the highest annual cost savings, averaged the savings, and directed the GMs to use this number as the sole performance criteria for compensation and retention purposes. Those that met the criteria were given handsome increases and those that didn't were put on employment probation. In an executive meeting, some of the GMs pointed out to Butch that the buyer's Performance Agreement also had project deliverables, teamwork, and supplier quality goals in addition to the cost reduction goals. Butch barked back, "Handle it!" 
FIG. 1 MEGAMATION OPERATIONS AND PRODUCT FLOW

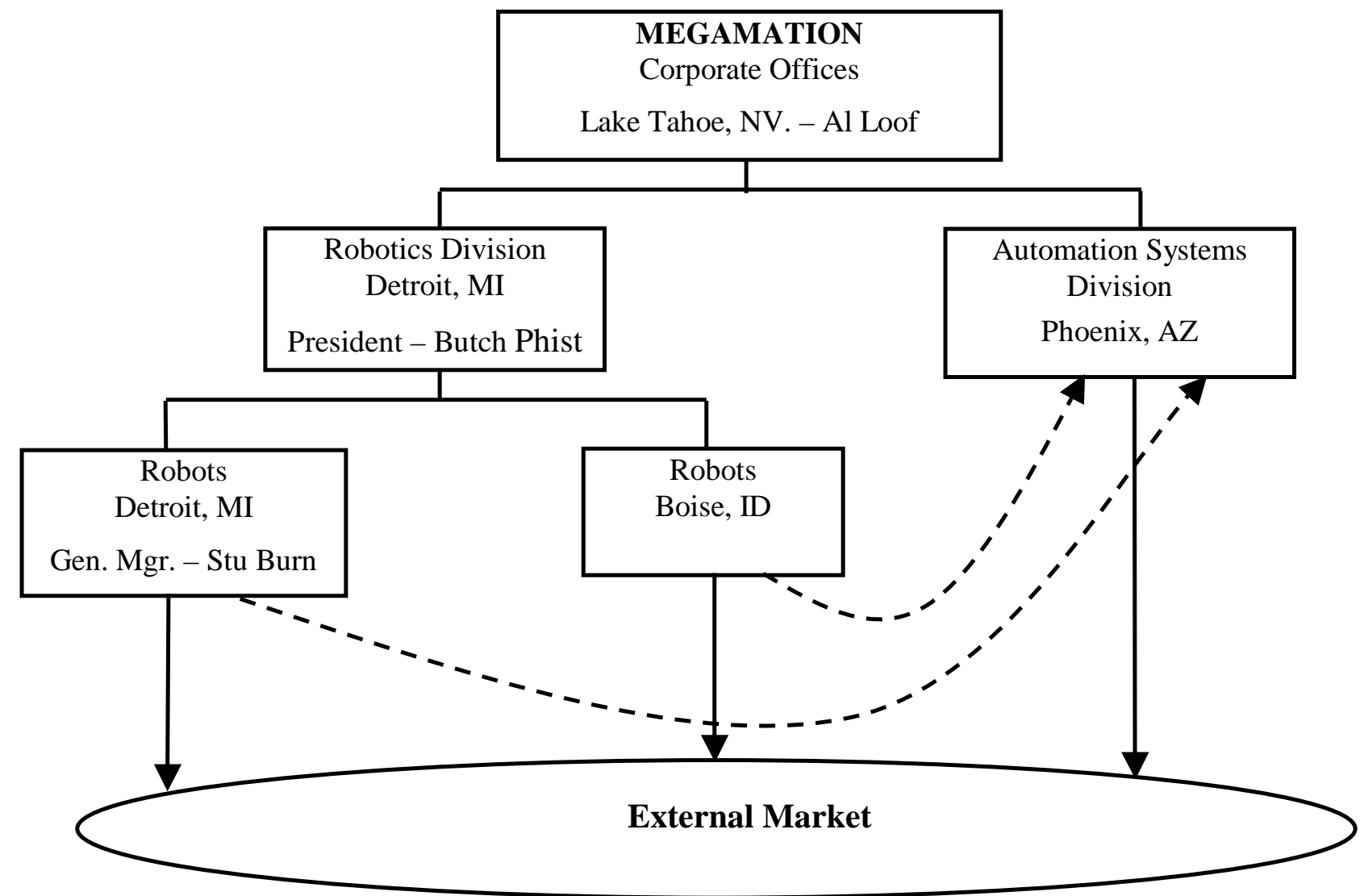

KEY:

$\longrightarrow$ Product Sold to the External Market

- - - Product Sold to the Internal Market

FIG. 2 BUTCH PHIST'S CAREER PATH

1997

1998

1999

2000

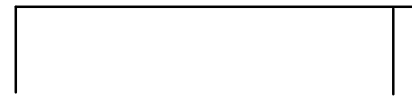

Director of Corporate

Purchasing

Chief Financial

Officer

Lake Tahoe

Lake Tahoe

President, Robotics

Division

Detroit

Proceedings of the 2001 American Society of Engineering Education Annual Conference and Exposition

Copyright @2001, American Society of Engineering Education 


\section{Butch Phist - President of the Robotics Division}

When Butch first took control of the Robotics Division, one of the first changes he made to Engineering was to "phase out" what he called the "highly compensated dead wood" and hire smart, young, college graduates. He believed that he could save hundreds of thousands of dollars in salaries. Besides, he could work directly with them to implement some ideas he had for new products in new markets. Butch enjoyed working with the new engineers even though he felt the majority of them were somewhat backward. Whenever he got the chance he would go downstairs and tell them what to do, so he didn't see the need to hire a new Engineering Manager to fill a position that had been open for over a year. The old Engineering Manager, Joe Trooth, had been transferred to purchasing and then "reduced" recently when he didn't "make the [cost reduction] numbers." This surprised many employees in the company because many of Joe's suppliers had received Quality awards from the Detroit Operations.

Even though the new engineers hadn't released any new products for over a year, Butch was satisfied with the cost savings to date and rationalized it would take awhile for the engineers to learn how to implement his ideas.

Most of the buyers in the Robotics Division were ex-engineers and were in their 50's. While they were engineers, many of them felt Megamation was causing Robotics to migrate too far away from their technological strengths and were not shy about voicing their opinions. It was clear to Butch that these " whining wienies" as he called them, simply weren't "on the team" and he was in the process of driving them out of the company or, as a last resort, terminating them when they could "not meet their numbers." The disadvantage of terminating them immediately was that Robotics always had to provide an attractive severance package in exchange for the employee's signature on a document that promised they would not sue the company for age discrimination or for some other reason.

Biff Adonis was one of the buyers who traditionally negotiated the greatest price reductions each year so he was selected to manage the Robotics Division's purchasing at the Detroit home offices.

\section{DETROIT OPERATIONS Quality Problems}

In the last two years, the average incoming quality level (AIQ) of the Robotics Division has been steadily decreasing from $99.5 \%$ to $95 \%$. This reduction of quality of purchased materials was becoming a serious problem for manufacturing. Not only was it causing an excessive amount of rework in manufacturing, it had also caused average outgoing quality (AOQ) to go down. With increasing frequency, Butch was receiving calls from sales reps and customers who were dissatisfied with the inconsistent quality of Detroit's products. In addition, he felt that the increasing level of customer dissatisfaction was a factor, along with price competitiveness, behind the falling volumes of the company. In fact, sales and production volumes had decreased enough to cause the reduction or cancellation of several 12-month purchase orders (POs) the Robotics Division had already given their suppliers. More than one supplier was 
concerned that they were going to get stuck with unusable inventory and so were threatening legal action because they had already built or purchased the material for the volume ordered by Robotics.

Butch asked Biff about this issue in a recent management meeting. Biff was puzzled about why AIQ continued to decrease and proceeded to defend his purchasing process. Biff explained, "We get the prints from whatever plant needs a new part, send them out to suppliers for quotation, and then we place the P.O. with the lowest bidder. Engineering then checks a few samples from the first shipment to make sure they work. Once we get Engineering to agree, we round up our annual marketing forecast to the supplier's next highest volume price break and then place a 12 month P.O."

Stu Burn, Director of Manufacturing, stated, "His people spend so much time resolving problems with purchased material and resolving customer complaints that he has no time left to pursue cost reductions." He added, "Every time we ask the pre-Madonna's in engineering for help they either were too busy working on far-out projects or they didn't know how to solve the problem." Upon hearing this, Butch slammed his fist on the table and bellowed at Stu, "Either reduce costs by $25 \%$ or you'll be looking for a job too!"

After Butch settled down, he indicated to Biff that the purchasing process sounded okay, so he concluded the problem must be in engineering. He promised himself to make a trip downstairs to engineering after the management meeting.

When Butch visited Engineering, he dropped in on Desiree Meeker, a particularly attractive electrical engineer, who was struggling with an oscilloscope. Desiree complained to him that she had filled out a purchase request for a Hewlett Packard Model 2034 Oscilloscope but instead received one manufactured by Cheepo. She stated, "The scope had supposedly the same specifications as the HP but didn't work nearly as well." Butch acted like he didn't hear her and, as always, told her how nice she looked in that dress, winked at her, and without giving her time to respond, told her how glad he was to have her on his staff. He then asked her where Edwin Gadget, a new Ph.D. in Electrical Engineering, was because he wanted to know how the project was going. Desiree wondered why Butch didn't ask her how the project was going since she had been with the company for over two years and was working on the same project.

\section{The Internal Business}

The Robotics Division sold robots to the Automation Systems Division, the sister division in the corporation. Because the Detroit plant was having difficulty remaining cost-competitive with external suppliers, Mr. Al Loof, the CEO of Megamation had recently encouraged each Division to get quotes on materials and components from both inside the company and outside suppliers. In the past, the Robotics Division enjoyed significant financial benefits from the internal business because their sister division had the edict to buy all their robots and components from Robotics. For this reason, the Robotics Division could charge attractive profit margins on their internal business, frequently even greater margins than they enjoyed with their external business. Now all this had changed. 
It was important to Butch to retain the internal business because it offered stable volumes, production visibility and attractive margins they did not always enjoy with their external customers. Lately, whenever the Robotics Division quoted on a part to be supplied by the Detroit Operations to ASD, they always seemed to lose the business to a competitor on the Pacific Rim even when Detroit Operations got the opportunity to evaluate the drawings and quote first. It didn't seem to matter what price Detroit Operations quoted to ASD, their price was always beaten by five percent or more. On the last part they quoted Automation Systems Division, Robotics quoted well below Detroit's manufacturing cost and still they lost the business to a competitor. Fortunately, the Boise Operation wasn't experiencing this problem on the parts that they were supplying to ASD. Their business actually grew somewhat both internally and externally.

\section{A Visit from Mr. Loof}

In the middle of Butch's contemplation on Detroit's rapidly decreasing internal business, Butch's secretary, Miss Kautau paged him and told him that Mr. Loof, the CEO, was in his office. Butch snapped back, "Get us some coffee, make him comfortable and I'll be right up!"

Butch hated Detroit and desperately wanted to return to corporate headquarters in Lake Tahoe. Profits of the Robotics Division were improving thanks to his cost reduction efforts in the overhead and purchased materials areas. He was uncertain about what direction to provide in order to reduce manufacturing costs further. Finally, he was worried about Detroit's decreasing sales numbers in both the internal and external business and how to return the operation to a time when revenues grew steadily year after year. Now, on top of all that, the CEO told him today to transfer all products from the Detroit Operations to the other Megamation operations at cost!

\section{Questions:}

1. Utilizing universal ethical principles, characterize Butch's management style and approach to doing business and then how you would change them if you were the CEO.

2. Identify all ethical, moral, or legal issues. Analyze them from the points of view of the individual and of the organization.

3. Develop an integrated comprehensive organizational plan for Butch that would allow them to continue to reduce costs and grow sales while improving their responsibility to the community. For example, address such areas as improving their business ethics and reducing the number of people "laid-off"? What kind of "politics" do you think might be working behind the scenes at Megamation? 